\title{
PRELIMINARY PHYTOCHEMICAL STUDY OF THE ECUADORIAN PLANT CROTON ELEGANS KUNTH (EUPHORBIACEAE)
}

\section{CLAUDIA HERRERA ${ }^{l}$, YANELY PÉREZ ${ }^{1}$, VLADIMIR MOROCHO ${ }^{l}$, CHABACO ARMIJOS ${ }^{l}$, OMAR MALAGÓN ${ }^{l}$, BEATRIZ BRITO ${ }^{3}$, MARCELO TACÁN ${ }^{3}$, LUIS CARTUCHEI, GIANLUCA GILARDONI, ${ }^{1,2, *}$}

\author{
${ }^{1}$ Departamento de Química y Ciencias Exactas, Universidad Técnica Particular de Loja (UTPL), Loja, Ecuador. \\ ${ }^{2}$ Prometeo Project Researcher, SENESCYT, Quito, Ecuador. \\ ${ }^{3}$ Instituto Nacional de Investigaciones Agropecuarias (INIAP), Panamericana Sur Km 1, Quito, Ecuador \\ *Corresponding author, UTPL, Calle Marcelino Champagnat s/n, 11-01-608, Loja, Ecuador.
}

\begin{abstract}
The species Croton elegans Kunth, belonging to the family Euphorbiaceae and known with the common name "mosquera", is a native medicinal plant of Ecuador. Due to its medical applications, we are interested in secondary metabolite composition. After extraction with hexane and preparation of the alkaloid extract, preparative chromatographic fractionation in both normal and direct phase was performed. ${ }^{1} \mathrm{H}$ NMR, ${ }^{13} \mathrm{C}$ NMR, HSQC and HMBC experiments, together with polarimetric measurements, were conducted in order to characterize the purified compunds. Two triterpene metabolites (friedelin and cycloeucalenol) and two morphinan alkaloids $((+)$-pallidine and $(+)-O$-methylpallidine) were obtained in a pure form. This work represents the first report on the phytochemistry of $C$. elegans and probably the second publication on the natural $(+)$-pallidine alkaloid.
\end{abstract}

Keywords: Croton elegans; alkaloid; secondary metabolite; Ecuador; NMR; mosquera; friedelin; cycloeucalenol; (+)-pallidine; (+)-O-methylpallidine.

\section{INTRODUCTION}

Ecuador is one of the 17 recognized megadiverse countries [1], i.e. one of the countries with the highest concentration of different botanical and animal living species on the planet. For this reason, Ecuador is a privileged place for chemical research on plants that were never studied before. Furthermore, in Ecuador many indigenous nations live with their ancestral knowledge, which includes traditional application of biological active plants to medicine and supernatural rites [2].

Croton elegans Kunth is an endemic species of Ecuador, belonging to the family Euphorbiaceae and known with the common name "mosquera". According to the Catalogue of the Vascular Plants of Ecuador [3], this species corresponds also to Croton ferrugineus var. elegans (Kunth) Moell. Arg.

Phytochemistry of C. elegans has not been reported previously in literature, for this reason we consider this work as the first chemical report on this plant. According to botanical literature, this plant is a shrub of the dry interandean vegetation, growing between 1500 and $3500 \mathrm{~m}$ a.s.l. and spread in the canton of Loja, south of Ecuador, where it is described as "locally very abundant" [4]. C. elegans was selected as an interesting item for two reasons. First of all because it presents many applications in the traditional medicine of Ecuador, in fact $C$. elegans is used as an anti-inflammatory, in the treatment of toothache, wounds, tonsillitis an warts. It is also a powerful purgative, that should be used very carefully as it can produce vomit and strong abdominal pain. It has also been used in the treatment of rheumatism, gout, neuralgia and bronchitis. On the other hand, it was selected also due to the phytochemical richness and phylogenetic variety of the genus [2]. Croton spp. are well known for producing terpene compounds, mainly diterpenes of the cembranoid, clerodane, neoclerodane, halimane, isopimarane, kaurane, secokaurane, labdane, phorbol and trachylobane families. Other important terpenic compounds present in Croton spp. are triterpenes and volatiles isoprenoids, that are constituents of essential oils, together with volatile shikimic acid derivatives [5]. The other great category of metabolites commonly found in this genus is constituted by alkaloids, whose presence is of the greatest interest due to the biological activities they often show [5]

From the pharmacological point of view, Croton spp. are known to possess a lot of activities, among them: anti-lipidemic, wound healing, anti-diarrheic, immunomodulatory, antibacterial, antifungal, antiviral, antimalarial, anticancer, anti-mutagenic, mutagenic, antioxidant, myorelaxant, antispasmodic, antihypertensive, anti-inflammatory, anti-nociceptive, etc [5].

\section{EXPERIMENTAL}

2.1 General information

The structural identification of friedelin, cycloeucalenol, (+)-pallidine and (+)-O-methylpallidine was performed through NMR, with a Varian
Agilent NMR instrument (Walnut Creek, CA, USA, $400 \mathrm{MHz}$ for ${ }^{1} \mathrm{H}$ and 100 $\mathrm{MHz}$ for ${ }^{13} \mathrm{C}$ experiments). Deuterated solvents were purchased from SigmaAldrich ${ }^{\circledR}$. Chemical shifts were reported in units (ppm) relative to the signal of tetramethylsilane (TMS) and coupling constants (J) in Hz. Rf values are referred to silica normal phase TLC, friedelin and cycloeucalenol were revealed with vanillin/sulphuric acid reagent [6], (+)-pallidine and (+)-O-methylpallidine were revealed with Dragendorff's reagent [6]. Yields are expressed as \% w/w referred to extracts.

\subsection{Plant material}

A few specimens of $C$. elegans were collected in February 2013 at the parish of Sagrario, canton Cotacachi, province of Imbabura, Ecuador. Plants were located at $2676 \mathrm{~m}$ a.s.l. After collection, they were reproduced in greenhouse at the conservation garden of Tumbaco (Pichincha). Leaves were collected and selected by a technician of INIAP and a botanical sample was prepared with voucher number MT-JA116, preserved by INIAP with the Germoplasm Bank number ECU-20046. The collection was performed under scientific investigation permission N. 004-12-IC-FLO-DNB/MA. After selection, the plant material was dried at $35^{\circ} \mathrm{C}$ and stored in a dark, dry and fresh place until processing

\subsection{Extraction}

$500 \mathrm{~g}$ of dry leaves were milled and exhaustively extracted with hexane, the solvent was then removed by vacuum distillation obtaining $20.6 \mathrm{~g}$ of dry extract. It was directly submitted to chromatographic fractionation, while the residual plant was submitted to acidic extraction in order to obtain the alkaloid fraction. In this case the plant was suspended in diluted aqueous sulphuric acid $(2 \% \mathrm{v} / \mathrm{v})$, the solid was filtered and the process repeated until negative reaction to Dragendorff's reagent. The reunited aqueous phases were alkalinized until $\mathrm{pH} 11$ by addition of concentrated ammonia, then extracted with chloroform until negative reaction to Dragendorff's reagent. After drying with anhydrous sodium sulphate, the reunited organic phases were distilled at reduced pressure, affording $1.9 \mathrm{~g}$ of alkaloid fraction. All organic solvents were technical grade, bought from Brenntag (Guayaquil, Ecuador) and carefully distilled before using.

\subsection{Isolation and purification}

$2.0 \mathrm{~g}$ of the hexane extract were fractionated by preparative liquid chromatography, applying a ratio of $100: 1 \mathrm{w} / \mathrm{w}$ between the stationary phase and the mixture. The process was performed on normal phase silica gel 60 $\AA(40-63 \mu \mathrm{m})$ purchased from Sigma-Aldrich, eluting through an increasing polarity gradient. The elution was performed with a mixture of hexane/EtOAc, from $95 \%$ of hexane to EtOAc $100 \%$. The fractions were analysed on silica TLC plates with fluorescent indicator at $254 \mathrm{~nm}$, purchased from SigmaAldrich, and reunited in relation to their composition. After exposure to UV 
light (254 and $366 \mathrm{~nm}$ ), TLC plates were revealed with sulphuric acid/vanillin reagent. Subsequent direct phase chromatographic fractionation of the impure fractions, performed in line with the same principles, afforded two major pure compounds, identified as friedelin (1) and cycloeucalenol (2).

For what concerns the alkaloid extract, the whole amount was submitted to both direct and C-18 reversed phase chromatography. The reversed phase fractionation was performed on the whole alkaloid extract, with LiChroprep ${ }^{\mathbb{B}}$ RP-18 (40-63 $\mu \mathrm{m})$ from Merck. The process was performed following an increasing gradient of eluotropic strength, eluting with a $\mathrm{MeOH} / \mathrm{H}_{2} \mathrm{O}$ from $80 \%$ until $100 \% \mathrm{MeOH}$. The column was packed with a ratio $100: 1 \mathrm{w} / \mathrm{w}$ between stationary phase and alkaloid mixture. The fractions obtained were analysed on Merck C-18 reversed phase TLC, with fluorescence indicator at $254 \mathrm{~nm}$. After exposure to UV light (254 and $366 \mathrm{~nm}$ ), TLC plates were revealed with Dragendorff's reagent [6]. Two major alkaloid fractions were then purified on silica, with the same stationary phase and ratio of the hexane extract. However, in this case the elution was performed with a mixture of hexane $/ \mathrm{CH}_{2} \mathrm{Cl}_{2} / \mathrm{MeOH}$ in an increasing polarity gradient from 50:40:10 to $\mathrm{CH}_{2} \mathrm{Cl}_{2} / \mathrm{MeOH} 90: 10$. Two pure alkaloid compounds were obtained and identified as (+)-pallidine (3) and (+)-O-methylpallidine (4). To purify both alkaloid and non-alkaloid compounds, the same solvents of the extraction process were applied.

2.5 Physical and Spectral Data of Isolated Compounds

Friedelin (1): $\mathrm{C}_{30} \mathrm{H}_{50} \mathrm{O}$; white crystals; yield $0.14 \%$; soluble in $\mathrm{CH}_{2} \mathrm{Cl}_{2}$ and $\mathrm{CHCl}_{3} ; \mathrm{Rf}=0.50$ (hexane/EtOAc 90:10); ${ }^{1} \mathrm{H} \mathrm{NMR}\left(\mathrm{CDCl}_{3}\right): \delta 2.39(1 \mathrm{H}$, dd, $\mathrm{J}=2.5,5.0, \mathrm{H}-2 \beta), 2.31(1 \mathrm{H}, \mathrm{dd}, \mathrm{J}=7.0,13.0, \mathrm{H}-2 \alpha), 2.25(1 \mathrm{H}, \mathrm{q}, \mathrm{J}=6.8, \mathrm{H}-4 \alpha)$, $1.97(1 \mathrm{H}, \mathrm{m}, \mathrm{H}-1 \alpha), 1.76(1 \mathrm{H}, \mathrm{dt}, \mathrm{J}=5.0,2.5, \mathrm{H}-6 \beta), 1.68(1 \mathrm{H}, \mathrm{dd}, \mathrm{J}=5.0,13.0$, $\mathrm{H}-1 \beta), 1.18$ (3H, s, H-28), 1.05 (3H, s, H-27), 1.01 (3H, s, H-30), 1.00 (3H, s, H-26), 0.95 (3H, s, H-29), 0.88 (3H, d, J=6.8, H-23), 0.87 (3H, s, H -25), 0.73 $(3 \mathrm{H}, \mathrm{s}, \mathrm{H}-24) ;{ }^{13} \mathrm{C}$ NMR $\left(\mathrm{CDCl}_{3}\right): \delta 213.4(\mathrm{C}-3), 59.6(\mathrm{C}-10), 58.3(\mathrm{C}-4), 53.2$ (C-8), 42.9 (C-18), 42.2 (C-5), 41.6 (C-2), 41.4 (C-6), 39.8 (C-13), 39.4 (C-22), 38.4 (C-14), 37.5 (C-9), 36.1 (C-16), 35.7 (C-11), 35.4 (C-19), 35.1 (C-29), 32.9 (C-15), 32.5 (C-21), 32.2 (C- 28), 31.9 (C-30), 30.6 (C-12), 30.1 (C-17), 28.3 (C-20), 22.4 (C-1), 20.4 (C-26), 18.8 (C-27), 18.3(C-7), 18.1 (C-25), 14.8 (C-24), 6.9 (C-23).

Cycloeucalenol (2): $\mathrm{C}_{30} \mathrm{H}_{50} \mathrm{O}$; white crystals; yield $0.08 \%$; soluble in

$\mathrm{CH}_{2} \mathrm{Cl}_{2}, \mathrm{CHCl}_{3}, \mathrm{MeOH} ; \mathrm{Rf}=0.30$ (hexane/EtOAc 90:10); ${ }^{1} \mathrm{H} \mathrm{NMR}\left(\mathrm{CDCl}_{3}\right)$ $\delta 4.70$ (1H, brs, H-28), $4.64(1 \mathrm{H}, \mathrm{d}, \mathrm{J}=1.2, \mathrm{H}-28), 3.22-3.16(1 \mathrm{H}, \mathrm{m}, \mathrm{H}-3), 2.22$ $(1 \mathrm{H}$, septet, J=6.8, H-25), 1,01 (3H, d, J=7.2, H-26), $1.00(3 \mathrm{H}, \mathrm{d}, \mathrm{J}=6.8, \mathrm{H}-27)$ $0.96(3 \mathrm{H}, \mathrm{d}, \mathrm{J}=7.2, \mathrm{H}-30), 0.95$ ( $3 \mathrm{H}, \mathrm{s}, \mathrm{H}-18), 0.88$ (3H, d, J=6.4, H-21), 0.87

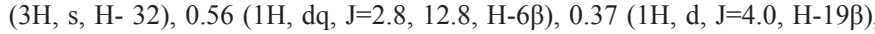
$0.18(1 \mathrm{H}, \mathrm{d}, \mathrm{J}=4.0, \mathrm{H}-19 \alpha) ;{ }^{13} \mathrm{C} \mathrm{NMR}\left(\mathrm{CDCl}_{3}\right): \delta 157.1(\mathrm{C}-24), 106.1(\mathrm{C}-28)$ 76.7 (C-3), 52.3 (C-17), 49.0 (C-14), 47.0 (C-8), 45.5 (C-13), 44.7 (C-4), 43.5 (C-5), 36.3 (C-20), 35.5 (C-15), 35.1 (C-22), 35.0 (C-2), 33.9 (C-25), 33.0 (C-12), 31.5 (C-23), 30.9 (C-1), 29.7 (C-10), 28.2 (C-16), 27.4 (C-19), 27.1 (C11), 25.3 (C-7), 24.8 (C- 6), 23.7 (C-9), 22.1 (C-26), 22.0 (C-27), 19.3 (C-32) 18.5 (C- 21), 17.9 (C-18), 14.5 (C-30).

(+)-pallidine (3): $\mathrm{C}_{19} \mathrm{H}_{21} \mathrm{NO}_{4}$; yellow solid; yield $0.73 \%$; soluble in $\mathrm{CH}_{2} \mathrm{Cl}_{2}, \mathrm{CHCl}_{3}, \mathrm{MeOH} ; \mathrm{Rf}=0.25$ (hexane/ $\mathrm{CHCl}_{3} / \mathrm{MeOH} 40: 55: 5$ ); $[\alpha]_{\mathrm{D}}{ }^{20}=$ $+20.3\left(\mathrm{c}=0.10, \mathrm{CHCl}_{3}\right) ;{ }^{1} \mathrm{H}$ NMR $\left(\mathrm{CDCl}_{3}\right): \delta 6.78(1 \mathrm{H}, \mathrm{s}, \mathrm{H}-4), 6.70(1 \mathrm{H}, \mathrm{s}$, H-1), $6.34(1 \mathrm{H}, \mathrm{s}, \mathrm{H}-5), 6.33(1 \mathrm{H}, \mathrm{s}, \mathrm{H}-8), 3.90(3 \mathrm{H}, \mathrm{s}, 3-\mathrm{MeO}), 3.80(3 \mathrm{H}, \mathrm{s}$ 6-MeO), $3.73(1 \mathrm{H}, \mathrm{d}, \mathrm{J}=6.0, \mathrm{H}-9), 3.36(1 \mathrm{H}, \mathrm{d}, \mathrm{J}=18.0, \mathrm{H}-10 \mathrm{a}), 3.04(1 \mathrm{H}, \mathrm{dd}$ $\mathrm{J}=18.0,6.4, \mathrm{H}-10 \mathrm{~b}), 2.67-2.62(2 \mathrm{H}, \mathrm{m}, \mathrm{H}-16), 2.49(3 \mathrm{H}, \mathrm{s}, \mathrm{N}-\mathrm{Me}), 1.96(1 \mathrm{H}$ $\mathrm{dt}, \mathrm{J}=6.0,12.8, \mathrm{H}-15 \mathrm{a}), 1.83(1 \mathrm{H}, \mathrm{dt}, \mathrm{J}=12.8,2.0, \mathrm{H}-15 \mathrm{~b}) ;{ }^{13} \mathrm{C} \mathrm{NMR}\left(\mathrm{CDCl}_{3}\right): \delta$ 180.8 (C-7), 160.1 (C-14), 151.6 (C-6), 146.0 (C-3), 145.1 (C-2), 129.5 (C-12) 129.0 (C-11), 122.9 (C-8), 118.8 (C-5), 113.7 (C-1), 107.6 (C-4), 61.0 (C-9), 56.3 (3-MeO), 55.3 (6-MeO), 45.8 (C-16), 42.3 (C-13), $41.6(\mathrm{~N}-\mathrm{Me}), 40.8$ (C15), 32.6 (C-10).

(+)-O-methylpallidine (4): $\mathrm{C}_{20} \mathrm{H}_{23} \mathrm{NO}_{4}$, yellow solid; yield 2.78\%; soluble in $\mathrm{CH}_{2} \mathrm{Cl}_{2}, \mathrm{CHCl}_{3}, \mathrm{MeOH} ; \mathrm{Rf}=0.35$ (hexane/ $\mathrm{CHCl}_{3} / \mathrm{MeOH} 40: 55: 5$ ); $[\alpha]^{20}=$ $+14.4\left(\mathrm{c}=0.08, \mathrm{CHCl}_{3}\right) ;{ }^{1} \mathrm{H}$ NMR $\left(\mathrm{CDCl}_{3}\right): \delta 6.81(1 \mathrm{H}, \mathrm{s}, \mathrm{H}-4), 6.63(1 \mathrm{H}, \mathrm{s}$, $\mathrm{H}-1), 6.35$ (1H, s, H-5), $6.33(1 \mathrm{H}, \mathrm{s}, \mathrm{H}-8), 3.88(3 \mathrm{H}, \mathrm{s}, 2-\mathrm{MeO}), 3.86(3 \mathrm{H}, \mathrm{s}$, $3-\mathrm{MeO}), 3.80(3 \mathrm{H}, \mathrm{s}, 6-\mathrm{MeO}), 3.69(1 \mathrm{H}, \mathrm{d}, \mathrm{J}=6.0, \mathrm{H}-9), 3.34(1 \mathrm{H}, \mathrm{d}, \mathrm{J}=18.0$ H-10a), 3.04 (1H, dd, J=18.0, 6.0, H-10b), 2.60-2.57 (2H, m, H-16), 2.47 (3H, s, N-Me), 1.99-1.91 (1H, m, H-15a), 1.86-1.82 (1H, m, H15b); ${ }^{13} \mathrm{C}$ NMR $\left(\mathrm{CDCl}_{3}\right): \delta 181.0(\mathrm{C}-7), 161.8(\mathrm{C}-14), 151.6(\mathrm{C}-6), 148.5(\mathrm{C}-3), 148.2(\mathrm{C}-2)$ 130.1 (C-12), 128.9 (C-11), 122.4 (C-8), 118.9 (C-5), 110.6 (C-1), 108.8 (C-4), 61.0 (C-9), 56.4 (6-MeO), 56.0 (3-MeO), 55.2 (2-MeO), 45.8 (C-16), 42.4 (C13), 41.9 (N-Me), 41.3 (C-15), 32.8 (C-10).

\section{RESULTS AND DISCUSSION}

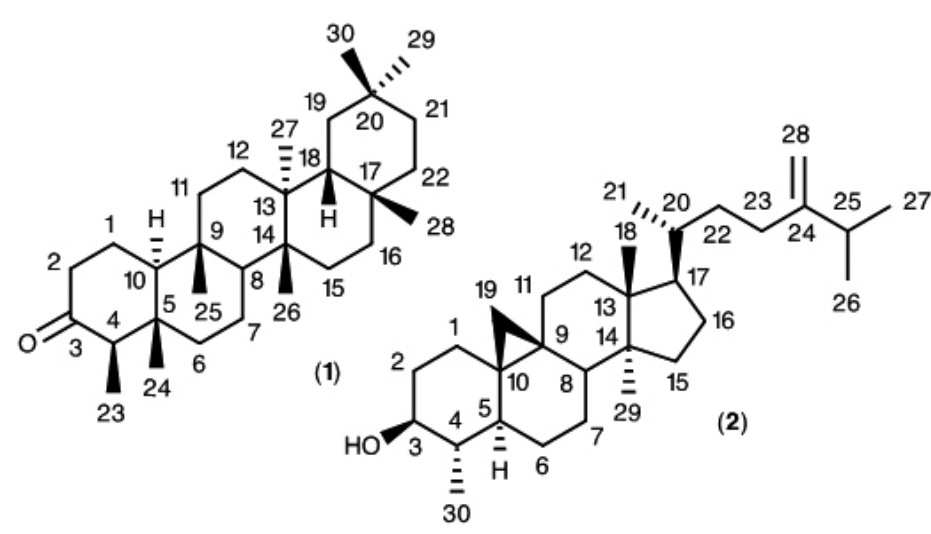

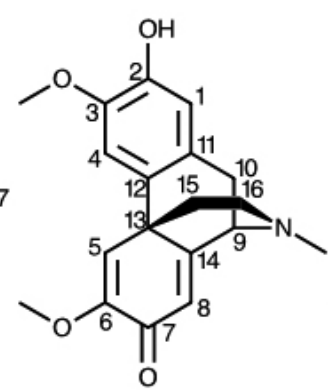

(3)

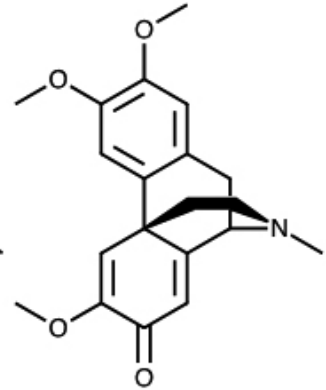

(4)

Figure 1. Secondary metabolites isolated from Croton elegans Kunth.

Friedelin (1) is a triterpenic carbonyl compound, quite common and well known since a long time as it was obtained in XIX century, in mixture with the $\alpha$-hydroxy derivative cerin. The structure was not completely elucidated until 1956, due to the study of Corey and Ursprung [7]. Since then, compound (1) has been found in many species, such as Kalanchoe daigremontiana [8], Acer mandshuricum [9], Maytenus rigida [10], Azima tetracantha [11] and Pterocarpus erinaceus [12].

Cycloeucalenol (2) is also a triterpenic metabolite, belonging to the family of cycloartanes. This class of molecules is also quite common and it is characterized by the presence of a cyclopropane condensed to ring B. I has been isolated from Boophone disticha [13], Fritillaria hupehensis [14], Brassica rapa [15], Erythrina stricta [16], Erythrina subumbrans [16], among others. According to bibliographic information, no one of these metabolites has been previously found in Croton sp.
Compounds (1) and (2) have been identified through ${ }^{1} \mathrm{H}$ and ${ }^{13} \mathrm{C}$ NMR experiments, by comparison of the respective spectra with literature $[17,18]$.

(+)-pallidine (3) and (+)-O-methylpallidine (4) are typical alkaloids of genus Croton, belonging to the family of morphinandienones $[5,19]$ $O$-methylpallidine (also known as $O$-methylflavinantine and sebiferine) is a quite common alkaloid in many vegetal species, both in (+) and (-) enantiomeric forms (Meconopsis horridula [20], Alseodaphne perakensis [21], Stephania bancroftii [22], Guatteria multivenia [23], Ocotea acutangula [24], Croton flavens $[25,26])$. On the other hand, pallidine is almost exclusively known as a natural compound in the levorotatory form. In fact, while (-)-pallidine has been found in many botanical species such as Ocotea acutangula [24], Corydalis pallida [27], Corydalis saxicola [28], Meconopsis cambrica [29] and Fumaria vaillantii [30], (+)-pallidine is mainly known as a synthetic compound [31]. Apparently, to date, the only known natural source of the dextrorotatory 
pallidine is Croton chilensis [32], the only Croton sp. growing in Chile [33].

Compounds (3) and (4) were characterized through ${ }^{1} \mathrm{H}$ and ${ }^{13} \mathrm{C}$ NMR experiments and optical activity. The spectra were compared with literature, resulting almost identical. Furthermore, HSQC and HMBC experiments were performed in order to confirm the position of $\mathrm{MeO}$ groups and respective signals (Table 1).

Table 1. HSQC and HMBC coupling for $\mathrm{MeO}$ groups of compounds (3) and (4).

\begin{tabular}{|c|c|c|}
\hline $\begin{array}{c}{ }^{1} \mathbf{H ~ N M R} \\
(\mathbf{p p m})\end{array}$ & $\begin{array}{c}\text { HSQC } \\
{ }^{13} \mathbf{C} \text { signal } \\
(\mathbf{p p m})\end{array}$ & $\begin{array}{c}\text { HMBC } \\
{ }^{13} \mathbf{C} \text { signal } \\
(\mathbf{p p m})\end{array}$ \\
\hline $3.90(3 \mathrm{H}, \mathrm{s})^{\mathrm{a}}$ & 56.3 & 146.0 \\
\hline $3.80(3 \mathrm{H}, \mathrm{s})^{\mathrm{a}}$ & 55.3 & 151.6 \\
\hline $3.88(3 \mathrm{H}, \mathrm{s})^{\mathrm{b}}$ & 55.2 & 148.2 \\
\hline $3.86(3 \mathrm{H}, \mathrm{s})^{\mathrm{b}}$ & 56.0 & 148.5 \\
\hline $3.80(3 \mathrm{H}, \mathrm{s})^{\mathrm{b}}$ & 56.4 & 151.6 \\
\hline
\end{tabular}

a(+)-pallidine, ${ }^{\mathrm{b}}(+)-O$-methylpallidine

\section{CONCLUSIONS}

The first preliminary phytochemical study on Croton elegans Kunth has been performed and described in this article. The most important result was the isolation of (+)-pallidine, an unusual enantiomer of the well-known pallidine alkaloid. In fact this enantiomer, whose stereochemistry has been proved by measuring its optical activity, is not usually the common stereoisomer found in nature. Apparently only in Croton chilensis, the only chilean plant of the genus, the same enantiomer has been described.

\section{ACKNOWLEDGMENTS}

This work was funded through the agreement N. 20120315 (PIC12 INIAP 002) by the Secretaría de Educación Superior, Ciencia, Tecnología e Innovación (SENESCYT) of Ecuador, and developed during the Prometeo Project fellowship (SENESCYT) of one of the authors (G.G.), in the period 2014-2015.

\section{REFERENCES}

1.- http://www.biodiversitya-z.org/content/megadiverse-countries

2.- O. Malagón, J. Ramírez, J.M. Andrade, V. Morocho, C. Armijos, G. Gilardoni, Nat. Prod. Comm. 11, 297 (2016).

3.- P.M. Jørgensen, S. León-Yánez, Catalogue of the Vascular Plants of Ecuador, Missouri Botanical Garden Press, St. Louis, 1999.

4.- S. León-Yánez, R. Valencia, N. Pitman, L. Endara, C. Ulloa Ulloa, H. Navarrete (eds.) Libro rojo de las plantas endémicas del Ecuador, 2 a edición. Publicaciones del Herbario QCA, Pontificia Universidad Católica del Ecuador, Quito, 2011.

5.- A. Salatino, M.L. Faria Salatino, G. Negri, J. Braz. Chem. Soc. 18, 11 (2007).

6.- H. Wagner, S. Bladt, Plant Drug Analysis - A Thin Layer Chromatography Atlas, Springer, Berlin, Heidelberg, 1996.

7.- E.J. Corey, J.J. Ursprung, J. Am. Chem. Soc. 78, 5041 (1956).

8.- Z. Wang, T. Yeats, H. Han, R. Jetter, J. Biol. Chem. 285, 29703 (2010)

9.- Y. Ding, C. Liang, J. Kim, Y.M. Lee, J.H. Hyun, H.K. Kang, J.A. Kim, B.S. Min, Y.H. Kim, Bioorg. Med. Chem. Letters 20, 1528 (2010).

10.- S. Martucciello, M.L. Balestrieri, F. Felice, C. Estevam, A.E. Goulart Sant'Ana, C. Pizza, S. Piacente, Chem. Biol. Inter. 183, 450 (2010).

11.- P. Antonisamy, V. Duraipandiyan, S. Ignacimuthu, J. Pharm. Pharmacol. 63, 1070 (2011)

12.- N. Ouédraogo, R.W. Sawadogo, A. Tibiri, C. Bayet, M. Lompo, A.E. Hay, J. Koudou, M.G. Dijoux, I.P. Guissou, Asian Pac. J. Trop. Med. , 46 (2012).

13.- E.A. Adewusi, P. Steenkamp, G. Fouche, V. Steenkamp, Nat. Prod. Comm. 8, $1213(2013)$

14.- H.F. Pi, P. Zhang, H.L. Ruan, Y.H. Zhang, H.D. Sun, J.Z. Wu, J. Asian Nat. Prod. Res. 11, 779 (2009).

15.- Y.H. Li, Y.F. Yang, K. Li, L.L. Jin, N.Y. Yang, D.Y. Kong, Chem. Pharm. Bull. 57, 401 (2009).
16.- T. Rukachaisirikul, A. Saekee, C. Tharibun, S. Watkuolham, A Suksamrarn, Arch. Pharm. Res. 30, 1389 (2007).

17.- D. Menezes de Oliveira, W. da Nova Mussel, L.P. Duarte, G.D. Silva, H.A. Duarte, E. C. de Lima Gomes, L. Guimarães, S.A. Vieira Filho, Quim. Nova 35, 1916 (2012).

18.- T. Kikuchi, S. Kadota, K. Tsubono, Chem. Pharm. Bull. 34, 2479 (1986).

19.- K.L. Stuart, Chem. Rev. 71, 47 (1971)

20.- J. Liu, H. Wu, F. Zheng, W. Liu, F. Feng, N. Xie, J. Sep. Sci. 37, 2513 (2014).

21.- N. Ahmat Abdul Hamid, J. Latip, I.M. Said, L.B. Din, Malaysian J. Sci. 24, 33 (2005).

22.- J.P. Bartley, L.T. Baker, C.F. Carvalho, Phytochemistry 36, 1327 (1994).

23.- Z. Zhang, H.N. El Sohly, M.R. Jacob, D.S. Pasco, L.A. Walker, A.M. Clark, J. Nat. Prod. 65, 856 (2002).

24.- V. Vecchietti, C. Casagrande, G. Ferrari, B. Danieli, G. Palmisano, J Chem. Soc. Perkin Trans. 1, 578 (1981).

25.- K.L. Stuart, C. Chambers, D. Byfield, J. Chem. Soc. (C), 1681 (1969).

26.- W.J. Eisenreich, G. Höfner, F. Bracher, Nat. Prod. Res. 17, 437 (2003)

27.- T. Kametani, M. Ihara, T. Honda, Chem Comm., 1301 (1969).

28.- X. Cheng, D. Wang, L. Jiang, D. Yang, Chem. Biodiv. 5, 1335 (2008).

29.- S.R. Hemingway, J.D. Phillipson, R. Verpoorte, J. Nat. Prod. 44, 67 (1981).

30.- M. Shamma, P. Chinnasami, S.F. Hussain, F. Khan, Phytochemistry 15, 1802 (1976).

31.- B. Franck, G. Dunkelinann, H.J. Lubs, Angew. Chem. 79, 1066 (1967).

32.- M. Bittner, M. Silva, P. Aqueveque, J. Kufer, J. Jakupovic, R. Murillo, Bol Soc. Chil. Quim. 42, 223 (1997).

33.- M. Bittner, J. Alarcón, P. Aqueveque, J. Becerra, V. Hernández, M. Hoeneisen, M. Silva, Bol. Soc. Chil. Quim. 46, 419 (2001). 